\title{
Daidzein impairs Leydig cell testosterone production and Sertoli cell function in neonatal mouse testes: An in vitro study
}

\author{
YANFENG ZHU ${ }^{1,2}$, HUA XU $^{1}$, MIN LI $^{3}$, ZHIBIN GAO $^{1}$, JIE HUANG $^{1}$, \\ LINXI LIU ${ }^{1}$, XIAOMING HUANG ${ }^{3}$ and YUN LI ${ }^{1}$ \\ ${ }^{1}$ Department of Nutrition, Food Safety and Toxicology, West China School of Public Health, Sichuan University, \\ Chengdu, Sichuan 610041; ${ }^{2}$ Department of Public Health, Chengdu Medical College, Chengdu, Sichuan 610500; \\ ${ }^{3}$ Department of Public Health, Luzhou Medical College, Luzhou, Sichuan 646000, P.R. China
}

Received September 22, 2015; Accepted September 26, 2016

DOI: $10.3892 / \mathrm{mmr} .2016 .5896$

\begin{abstract}
Isoflavone is a type of phytoestrogen that exists in soy-based products. Previous studies have reported that certain foods containing isoflavones, particularly infant formula, may have potential adverse effects on male reproductive function. However, few studies have focused on the effects of isoflavones on testosterone biosynthesis and Sertoli cell function during the neonatal period. The aim of the present study was to investigate the influence of daidzein, a common isoflavone, on testosterone secretion and Sertoli cell function during the neonatal period. The organ culture method was used to assess the effects of daidzein on neonatal mouse testes. Cultured testes were treated with daidzein $(0,0.03,0.3$, 3 or $30 \mu \mathrm{mol} / \mathrm{l}$ ) for $72 \mathrm{~h}$. To verify the mechanism of action of daidzein on androgen production, Leydig cells were also treated with daidzein for $24 \mathrm{~h}$. As anticipated, testosterone secretions were suppressed by daidzein $(30 \mu \mathrm{mol} / \mathrm{l})$ in cultured testes and Leydig cells. Further analysis demonstrated that the expression levels of steroidogenic acute regulatory protein (StAR), cholesterol side-chain cleavage enzyme (P450scc) and $3 \beta$-hydroxysteroid dehydrogenase ( $3 \beta-\mathrm{HSD})$, which are transport proteins and key enzymes in androgen biosynthesis, were suppressed in cultured neonatal mouse testes. In addition, the expression levels of StAR, P450scc, 3 $\beta$-HSD and $17 \alpha$-hydroxylase/20-lyase were decreased in Leydig cells. Notably, proliferation of Sertoli cells was also inhibited by daidzein $(30 \mu \mathrm{mol} / \mathrm{l})$. Furthermore, the expression levels of vimentin were significantly suppressed in the testes following treatment with daidzein, whereas inhibin B expression exhibited no change. In conclusion, daidzein may suppress
\end{abstract}

Correspondence to: Dr Yun Li, Department of Nutrition, Food Safety and Toxicology, West China School of Public Health, Sichuan University, 17 People's South Road, Chengdu, Sichuan 610041, P.R. China

E-mail: liyun_611@163.com

Key words: daidzein, Leydig cell, organ culture, Sertoli cell, testis, testosterone steroidogenic capability and impair Sertoli cell function in the neonatal period in vitro.

\section{Introduction}

There is growing public concern regarding the adverse effects of environmental chemicals with an estrogenic influence on reproductive health. Phytoestrogens, including daidzein, genistein and coumestrol, are defined as estrogenic compounds. Daidzein and genistein, among all types of isoflavones, are widely distributed in the daily human diet (1). In a typical Western diet, an average of $0.2 \mathrm{mg} / \mathrm{kg}$ isoflavones are consumed daily, whereas a typical Asian diet contains $>1.5 \mathrm{mg} / \mathrm{kg}$ isoflavones per day (2), which can raise individual human isoflavone serum levels to $500 \mathrm{nM}$ (3). For infants fed soy-based formulas, isoflavone intake can reach $9.3 \mathrm{mg} / \mathrm{kg} \cdot \mathrm{bw} /$ day (4).

Various studies have demonstrated that isoflavones provide a protective barrier against cancers, osteoporosis, menopausal syndromes and cardiovascular diseases (5-9). These findings have evoked strong public and academic interest in isoflavones. However, the negative effects of isoflavones, particularly on the male reproductive system, have also been reported (10). Previous studies demonstrated that isoflavones may produce male reproductive toxicity; their main adverse effects on the male reproductive system include the disturbance of sex hormone release $(11,12)$, interference with the onset of puberty (13), altering penile corpus cavernosum structure, weakening erectile function $(14,15)$, suppressing the activity of some steroidogenesis-associated enzymes (16), and decreasing the weight and epithelial height of accessory sex organs (12). Furthermore, a high intake of soy-based food and soy isoflavones is associated with reduced sperm concentration, as demonstrated in animal experiments and human epidemiological studies $(17,18)$. As aforementioned, infants fed soy-based formulas may be exposed to isoflavones, which may exert potential adverse effects. Although previous in vivo experiments have been conducted to determine the effects of isoflavone exposure on the testes (10), data regarding exposure to isoflavones during the early neonatal period is limited.

The mechanism underlying the effects of isoflavone exposure on male reproductive function is not fully understood. 
Several studies have reported that the effects of isoflavone exposure differ to those of estradiol (19), which implies that they may have different mechanisms of action. Isoflavones can suppress testosterone production in Leydig cells by direct inhibition of $3 \beta$-hydroxysteroid dehydrogenase ( $3 \beta$-HSD) activity, and induce adiponectin secretion, which can further suppress steroidogenic acute regulatory protein (StAR) expression and decrease testosterone (20). However, existing studies cannot fully explain the observed toxic phenomena associated with isoflavone exposure; for example, the associated decreased testosterone levels and sperm count.

The present study aimed to explore the effects of daidzein, a major type of isoflavone, on testes in the early neonatal period. A testis culture system was used, in which the testicular architecture was conserved and its development remains similar to that in vivo $(21,22)$, in order to explore the effects of daidzein exposure on steroidogenesis and Sertoli cell function. A cell culture experiment was also performed. The results of the present study may partially explain the adverse effects of daidzein on testes.

\section{Materials and methods}

Reagents. Daidzein (CAS\# 486-66-8; purity $\geq 98 \%$ ) was purchased from Sigma-Aldrich (Merck Millipore, Darmstadt, Germany). Daidzein stock solution was generated using dimethyl sulfoxide (DMSO; Amresco, LLC, Cleveland, $\mathrm{OH}$, USA) and was diluted in culture medium.

Experimental animals. Male neonatal mice (postnatal day 4) Kunming mice were obtained from the Experimental Animal Center of Sichuan University (SYXK 2009-045; Chengdu, China) and 10-15 mice were used. The animals were maintained at $25^{\circ} \mathrm{C}$, with access to food and water ad libitum and a 12-h light/dark cycle. All animal studies were conducted in accordance with the principles and procedures for the care and use of laboratory animals. The present study was approved by the ethics committee of West China School of Public Health, Sichuan University (Chengdu, China).

Organ culture and treatment. Organ culture was performed as described in our previous studies $(23,24)$. The mice were anesthetized and sacrificed by decapitation. Testes obtained from neonatal mice [postnatal day 4 (PND4), 10-15 mice] were isolated and cut into six to eight pieces. The pieces were pooled and transferred into $50 \mathrm{ml}$ bottles containing $6 \mathrm{ml}$ culture medium; six or more pieces were randomly put into each bottle. The bottles were attached to a rotator at $30 \mathrm{rpm}$ and were incubated at $34^{\circ} \mathrm{C}$ for $72 \mathrm{~h}$. Organ culture of the testes was performed in Dulbecco's modified Eagle's medium (DMEM)/F-12 (Hali Biotech, Chengdu, China) supplemented with $10 \%$ calf serum (Hali Biotech), $15 \mathrm{mmol} / 1$ HEPES ( $\mathrm{pH} 7.4), 5 \mu \mathrm{g} / \mathrm{ml}$ transferrin, $10 \mu \mathrm{g} / \mathrm{ml}$ insulin, $2 \mathrm{mmol} / 1$ glutamine, $100 \mathrm{U} / \mathrm{ml}$ penicillin $\mathrm{G}$ and $100 \mu \mathrm{g} / \mathrm{ml}$ streptomycin. The culture medium was collected and changed daily. Mixed gas comprised of $50 \% \mathrm{O}_{2}, 45 \% \mathrm{~N}_{2}$ and $5 \% \mathrm{CO}_{2}$ was injected into the bottles to maintain a fresh atmosphere, as previously stated $(24,25)$. Testes were assigned to five groups: Control group and daidzein-treated groups $(0.03,0.3,3$ and $30 \mu \mathrm{mol} / \mathrm{l})$. At the end of the $72 \mathrm{~h}$ culture, the testes were fixed for $12 \mathrm{~h}$ in
Bouin's fluid (trinitrophenol:methanal:ethanoic acid =15:5:1) at $4^{\circ} \mathrm{C}$, embedded in paraffin and cut into $5 \mu \mathrm{m}$ sections. The media were collected and stored at $-80^{\circ} \mathrm{C}$ for the subsequent testosterone radioimmunoassay. For mRNA analysis, testes were collected and immediately frozen in liquid nitrogen. Furthermore, $30 \mu \mathrm{g} / \mathrm{ml}$ 5'-bromo-2'-deoxyuridine (BrdU) was mixed into the culture system $3 \mathrm{~h}$ prior to testis harvesting to determine proliferation of Sertoli cells. The data were obtained from at least three independently repeated culture bottles.

Leydig cell culture and treatment. Leydig cells were obtained from the testes of male preadolescent mice (10-15 mice; age, 18-21 days) following euthanasia by decapitation under anesthesia. Subsequently, Leydig cells were isolated by a combination of collagenase digestion and Percoll density centrifugation. After digestion with $8 \mathrm{ml}$ collagenase II with $1.5 \%$ bovine serum albumin (BSA; Sigma-Aldrich; Merck Millipore) at $35^{\circ} \mathrm{C}$ for $25 \mathrm{~min}$, and prior to Percoll density centrifugation, seminiferous tubules were removed by passage of testicular fractions through a 200-mesh filter. The dispersed cells were washed with DMEM/F12 and layered over a Percoll gradient (70, 58, 30 and 5\%; Pharmacia Biotech; GE Healthcare, Uppsala, Sweden). The gradient was centrifuged for $30 \mathrm{~min}$ at $1,500 \mathrm{x} \mathrm{g}$, and cells localized between Percoll gradient 70 and 58\% were isolated. This step ensured the removal of heavier red blood cells and lighter germ cells.

To determine the purity of the target cells, enzyme histochemical and immunocytochemical methods were used to detect $3 \beta$-HSD. After a $24 \mathrm{~h}$ culture period, purified Leydig cells were incubated for $60 \mathrm{~min}$ at $34^{\circ} \mathrm{C}$ in a phosphate buffer solution containing $10 \%$ nitroblue tetrazolinum (Amresco, LLC), 10\% nicotanamide adenosine dinucleotide (Amresco, LLC), 6\% DHEA (Merck Millipore) and 6\% DMSO (26). Positive cells (containing blue granules) were identified as Leydig cells. In addition, Leydig cell slides were fixed with $4 \%$ paraformaldehyde, and were then immunostained according to standard protocol. Briefly, fixed cell slides were treated with 5\% Triton X-100 and sealed with 5\% BSA. Subsequently, the slides were incubated with $3 \beta$-HSD antibodies $(1: 800$; BIOSS, Beijing, China; cat. no. bs-3906R) overnight at $4^{\circ} \mathrm{C}$, then incubated with a secondary antibody working solution from an immunohistochemistry kit (SP-9000; ZSGB-BIO) for a further $15 \mathrm{~min}$ at room temperature, followed by incubation with avidin-biotin peroxidase complex for $15 \mathrm{~min}$. DAB was used as the chromogen and slides were observed under a light microscope. Leydig cells were typically $90 \%$ pure as assessed by these two staining methods.

Leydig cells were cultured in the same DMEM/F12 medium as the organ culture. Leydig cells ( $3 \times 10^{5} / 1 \mathrm{ml}$ medium) were plated into six-well plates and were cultured at $34^{\circ} \mathrm{C}$ in a humidified atmosphere containing $95 \%$ air and $5 \% \mathrm{CO}_{2}$. A total of 1 day after plating, fresh medium was added, and treatments were initiated. Doses of daidzein were added to wells in triplicate, and cells were cultured at $34^{\circ} \mathrm{C}$ in a humidified atmosphere containing $5 \% \mathrm{CO}_{2}$ for $24 \mathrm{~h}$. Subsequently, the medium was collected and stored at $-20^{\circ} \mathrm{C}$ until further analysis.

Assessment of cellular viability. Cellular viability was evaluated using the MTT proliferation assay. Briefly, cells were 
plated in a 96-well plate at a density of 10,000 cells/well. Following 24 or $48 \mathrm{~h}$ incubation at $37^{\circ} \mathrm{C}$ with various concentrations of daidzein, $20 \mu \mathrm{l}$ MTT was added to each well and the cells were incubated for $4 \mathrm{~h}$ at $37^{\circ} \mathrm{C}$. Subsequently, the medium was replaced with $150 \mu \mathrm{l} \mathrm{DMSO}$ and the cells were oscillated for $15 \mathrm{~min}$. Finally, absorbance was measured at $490 \mathrm{~nm}$. Results were presented as a percentage of the control values from untreated cells.

Measurement of testosterone production. Testosterone secreted into the culture medium was determined in duplicate by Iodine [125I] Testosterone Radioimmunoassay kit (Beijing North Institute of Biological Technology, Beijing, China), according to the manufacturer's protocol.

Histopathology and immunohistochemistry. Histopathological evaluation was conducted using hematoxylin and eosin (H\&E) staining. Following fixation in Bouin's fixative and dehydration, the testes were embedded in paraffin and cut into $5 \mu \mathrm{m}$ sections. Sections from the testes were stained with H\&E for histopathological evaluation, hematoxylin was applied for $5 \mathrm{~min}$ and eosin for $2 \mathrm{~min}$ (both at room temperature). Protein expression in tissue was detected by immunohistochemical staining. Serial sections ( $5 \mu \mathrm{m})$ were then mounted on slides, deparaffinized with xylene twice for $15 \mathrm{~min}$ and rehydrated in an alcohol gradient. The sections were then immunostained with antibodies according to manufacturer's protocol. For antigen retrieval, sections were microwaved at $450 \mathrm{~W}$ in $10 \mathrm{mmol} / \mathrm{l}$ citrate buffer solution. For all immunohistological procedures, slides were treated with Triton X-100 for $1 \mathrm{~min}$, and were then incubated in $0.3 \% \mathrm{H}_{2} \mathrm{O}_{2}$ for $10 \mathrm{~min}$ and in 5\% normal goat serum albumin (ZSGB-BIO, Beijing, China) in PBS for $1 \mathrm{~h}$, in order to block nonspecific antigen-binding. Subsequently, the slides were incubated with the following primary antibodies: Anti-3 $\beta$-HSD (1:800), anti-cholesterol side chain cleavage enzyme (P450scc; 1:200; Wuhan Boster Biological Technology Co., Ltd., Wuhan, China; cat. no. BA3699), anti-17 $\alpha$-hydroxylase/20-lyase (P450C17 $\alpha$; 1:200; BIOSS; cat. no. bs-6695R), anti-vimentin (1:400; BIOSS; cat. no. bs-8533R) and anti-BrdU (1:100; Sigma-Aldrich; Merck Millipore; cat. no. B2531) overnight at $4^{\circ} \mathrm{C}$. The primary antibodies were detected by incubation with a secondary antibody working solution from a immunohistochemistry kit (SP-9000; ZSGB-BIO) for a further $15 \mathrm{~min}$ at room temperature, followed by incubation with avidin-biotin peroxidase complex (Vector Laboratories, Inc., Burlingame, USA) for $15 \mathrm{~min}$. 3',3'-Diaminobenzidine (ZSGB-BIO) was used as the chromogen and hematoxylin as the nuclear counterstain. Negative control refers to samples in which the primary antibody was omitted. Staining was observed under a light microscope.

RNA extraction, reverse transcription and quantitative polymerase chain reaction $(q P C R)$. Testes were collected and homogenized, followed by total RNA extraction from the testes and cells using the MicroElute Total RNA kit (Omega Bio-tek, Norcross, GA, USA), and $0.8 \mu \mathrm{g}$ total RNA was reverse transcribed using Oligo (dT) 18 primers and RevertAid M-MuLV reverse transcriptase (Thermo Fisher Scientific, Inc., Waltham, MA, USA) in a $20 \mu \mathrm{l}$ reaction mixture, according to the manufacturer's protocol. To determine the expression levels of mRNAs that code for proteins implicated in
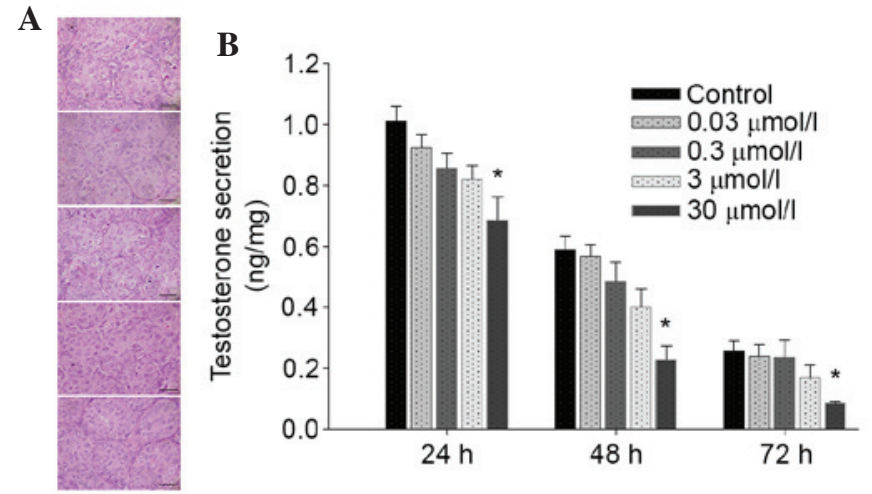

Figure 1. Effects of daidzein exposure on testosterone secretion in neonatal mouse testes. (A) Photomicrograph of testes sections after hematoxylin and eosin staining. Scale bars $=20 \mu \mathrm{m}$. (B) Testosterone secretion in testis cultures in the absence or presence of daidzein. Data are presented as the mean \pm standard error from three cultures. ${ }^{*} \mathrm{P}<0.05$ vs. control.

the steroidogenic pathway (StAR, P450scc, P450C17 $\alpha$ and $3 \beta-H S D)$, qPCR amplification was performed using a Bio-Rad CFX96 Detector system and SsoFast EvaGreen Supermix (Bio-Rad Laboratories, Inc., Hercules, CA, USA). A reaction volume of $10 \mu \mathrm{l}$ was used containing $2 \mu \mathrm{l}$ cDNA, $5 \mu 1$ supermix, $0.2 \mu \mathrm{l}$ each primer and 2.6 $\mu \mathrm{l}$ RNase/DNase-free water. The thermocycling conditions were as follows: Initial denaturation at $95^{\circ} \mathrm{C}$ for $30 \mathrm{sec}$; followed by 35 cycles of $95^{\circ} \mathrm{C}$ for $5 \mathrm{sec}$ and Tm for $5 \mathrm{sec}$. Tm was $60^{\circ} \mathrm{C}$ for StAR and $\mathrm{p} 450 \mathrm{c} 17 \alpha, 55^{\circ} \mathrm{C}$ for $\mathrm{P} 450$ scc and $3 \beta$-HSD, $56.3^{\circ} \mathrm{C}$ for inhibin $\mathrm{B}, 57.4$ for vimentin and 57.4 for $\beta$-actin. In testes, the expression levels of inhibin $B$ and vimentin were also detected. The primers used were as follows: StAR, forward (f) 5'-cgggtggatgggtcaagttc-3', reverse (r) 5'-ccaagcgaaacaccttgcc-3'; p450scc, f 5'-acatggccaagatgg tacagttg-3', r 5'-acgaagcaccaggtcattcac-3'; 3 $\beta$-HSD, f 5'-tggaca aagtattccgaccaga-3', r 5'-ggcacacttgcttgaacacag-3'; p450c17 $\alpha, \mathrm{f}$ 5'-tgaccagtatgtaggcttcagtcg-3', r 5'-tccttcgggatggcaaactctc-3'; vimentin f 5'-cgtccacacgcacctacag-3', r 5'-gggggatgaggaata gaggct-3'; and inhibin B, f 5'-cttcgtctctaatgaaggcaacc-3', and r 5'-ctccaccacattccacctgtc-3'. Gene expression was normalized to the housekeeping gene $\beta$-actin: F 5'-ggctgtattccctc catcg-3' and R 5'-ccagttggtaacaatgccatgt-3', and expression levels are presented relative to vehicle control (DMSO) at the same time point. All samples were run together in triplicate. Quantification cycle $(\mathrm{Cq})$ values obtained for triplicates were averaged and normalized to $\beta$-actin for each RNA sample. Analyses were performed using the $2^{-\Delta \Delta C q}$ method (27).

Western blot analysis. Leydig cells were washed with PBS and lysed in cell lysis/extraction reagent (Nanjing KeyGen Biotech, Co., Ltd., Nanjing, China), including phenylmethanesulfonyl fluoride. Protein concentration was quantified using the Bradford method. Proteins $(40 \mu \mathrm{g})$ were separated by $10 \%$ SDS-PAGE, and were then electrophoretically transferred onto polyvinylidene fluoride (PVDF) membranes. The blots were incubated at $4{ }^{\circ} \mathrm{C}$ overnight with specific primary antibodies against StAR (1:100; cat. no. sc-25806), P450scc (1:200; cat. no. 18043), P450C17 $\alpha$ (1:200; cat. no. 66850) and $3 \beta-\mathrm{HSD}$ (1:200; cat. no. sc-28206), all obtained from Santa Cruz Biotechnology, Inc., Dallas, TX, USA) and $\beta$-actin $(1: 1,000$; ZSGB-BIO; cat. no. TA-09). Subsequently, membranes were 
A

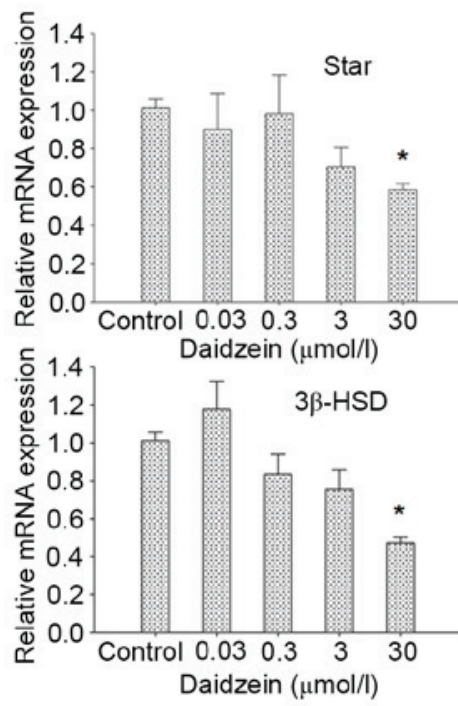

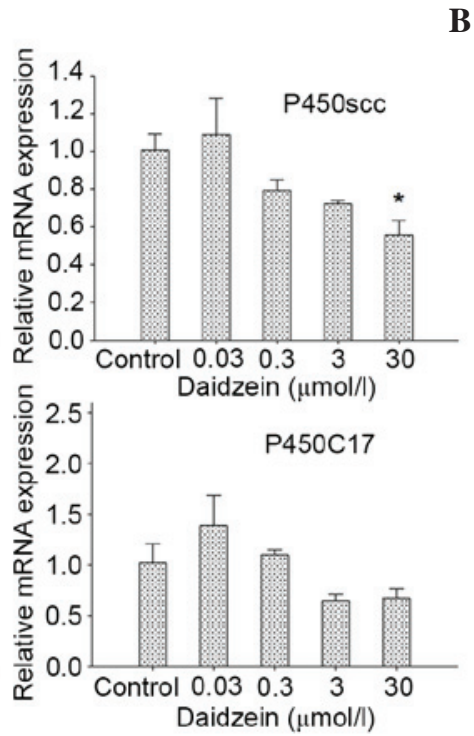

B

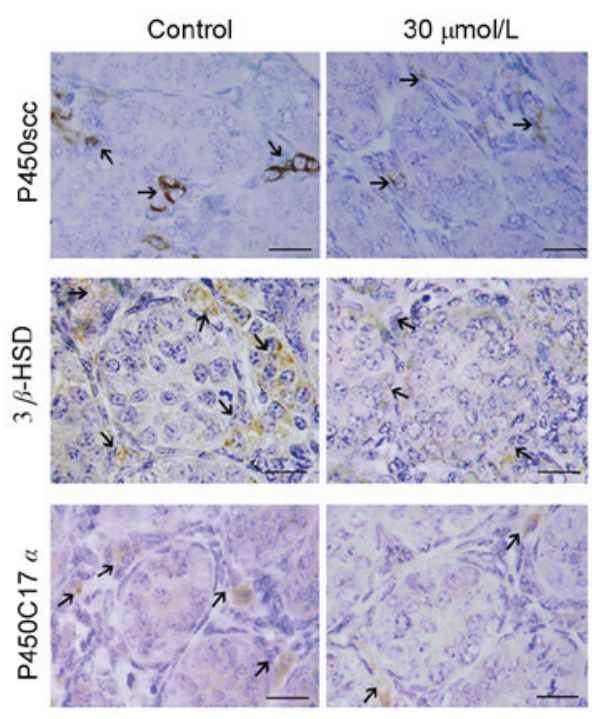

Figure 2. Effects of daidzein on StAR and steroidogenic enzyme expression in the testes. (A) Quantitative polymerase chain reaction analyses of StAR, P450scc, 3 $\beta$-HSD and P450C17 $\alpha$ mRNA expression. Data are presented as the mean \pm standard error $\left(\mathrm{n}=3\right.$ ). ${ }^{*} \mathrm{P}<0.05$ vs. the control. (B) Immunohistochemical staining of $\mathrm{P} 450 \mathrm{scc}, 3 \beta$-HSD and $\mathrm{P} 450 \mathrm{C} 17 \alpha$. Arrows indicate positive staining; scale bars $=20 \mu \mathrm{m}$. StAR, steroidogenic acute regulatory protein; P450scc, anti-cholesterol side chain cleavage enzyme; 3 $\beta$-HSD, 3 $\beta$-hydroxysteroid dehydrogenase; P450C17 $\alpha$, 17 $\alpha$-hydroxylase/20-lyase.

incubated with secondary antibodies (1:5,000; Santa Cruz Biotechnology, Inc.; cat. nos. sc-2004 and sc-2020) for $1 \mathrm{~h}$ at room temperature, according to the manufacturer's protocol. The membranes were then washed with TBS-Tween 20, and immunoreactivity was visualized using an enhanced chemiluminescence reagent and analyzed with ChemiDoc MP system and ImageLab 4.0 (Bio-Rad Laboratories, Inc.).

Measurement of inhibin B production. Inhibin B secreted into the medium by testes was detected by ELISA [Human/Mouse/Rat Inhibin B ( $\beta$ B subunit); RayBiotech, Norcross, GA, USA] according to the manufacturer's protocol. Absorbance was measured using an ELISA plate reader at a wavelength of $450 \mathrm{~nm}$.

Statistical analysis. All values are expressed as the mean \pm standard error. Statistical analysis was performed using one-way analysis of variance followed by Dunnett's t-test with SPSS 20.0 (IBM SPSS, Armonk, NY, USA). P<0.05 was considered to indicate a statistically significant difference.

\section{Results}

Exposure to daidzein suppresses testosterone secretion in testes without inducing histopathological changes. Testicular histopathology was observed $72 \mathrm{~h}$ following daidzein administration, and testosterone secreted by neonatal testes was collected every $24 \mathrm{~h}$ and analyzed. No obvious histopathological alterations were observed in the daidzein-treated testes (Fig. 1A). However, testosterone secretion by PND4 testes during 3 days of culture was reduced following incubation with $30 \mu \mathrm{mol} / 1$ daidzein (Fig. 1B).

Daidzein alleviates StAR and steroidogenic enzyme expression in testes. To determine the effects of daidzein on steroidogenic-related protein and enzyme expression in neonatal testes, qPCR and immunohistochemical analysis were performed. After 72 h culture with or without daidzein, the mRNA expression levels of StAR, P450scc and 3 $\beta$-HSD, which are involved in the steroidogenic process, were downregulated following treatment with $30 \mu \mathrm{mol} / 1$ daidzein compared with the control $(\mathrm{P}<0.05$; Fig. $2 \mathrm{~A})$. No obvious changes in the mRNA expression levels of $\mathrm{P} 450 \mathrm{C} 17 \alpha$ were detected .

Corresponding with the findings of $\mathrm{qPCR}$, the protein expression levels of P450scc and $3 \beta$-HSD in the testes were reduced following treatment with $30 \mu \mathrm{mol} / \mathrm{l}$ daidzein (Fig. 2B). No marked change in $\mathrm{P} 450 \mathrm{C} 17 \alpha$ staining intensity was detected.

Exposure to daidzein reduces testosterone production, and alters the expression of StAR and steroidogenic enzymes in Leydig cells. To further verify the effects of daidzein on testosterone production in testes, the present study investigated testosterone secretion, and StAR, P450scc, $3 \beta$-HSD and $\mathrm{P} 450 \mathrm{C} 17 \alpha$ expression in Leydig cells in vitro. Cell viability was analyzed by MTT assay, and no changes were observed (Fig. 3A). Consistent with organ culture, incubation with $30 \mu \mathrm{mol} / 1$ daidzein induced a marked suppression of testosterone production by Leydig cells compared with in the control cells $(\mathrm{P}<0.05$; Fig. $3 \mathrm{~B})$. The $\mathrm{qPCR}$ results indicated that the mRNA expression levels of StAR, P450scc, 3 $\beta$-HSD and $\mathrm{P} 450 \mathrm{C} 17 \alpha$ were lower following treatment with $30 \mu \mathrm{mol} / 1$ daidzein compared with the control $(\mathrm{P}<0.05$; Fig. $3 \mathrm{C})$.

The present study also examined the protein expression levels of StAR, P450scc, 3 $\beta$-HSD and P450C17 $\alpha$ in Leydig cells. StAR, P450scc, $3 \beta$-HSD and P450C17 $\alpha$ protein expression levels were decreased in Leydig cells exposed to daidzein (Fig. 3D). Collectively, these effects on mRNA and protein expression indicate that a general downregulation of the steroid synthesis pathway leads to the observed low testosterone levels. 

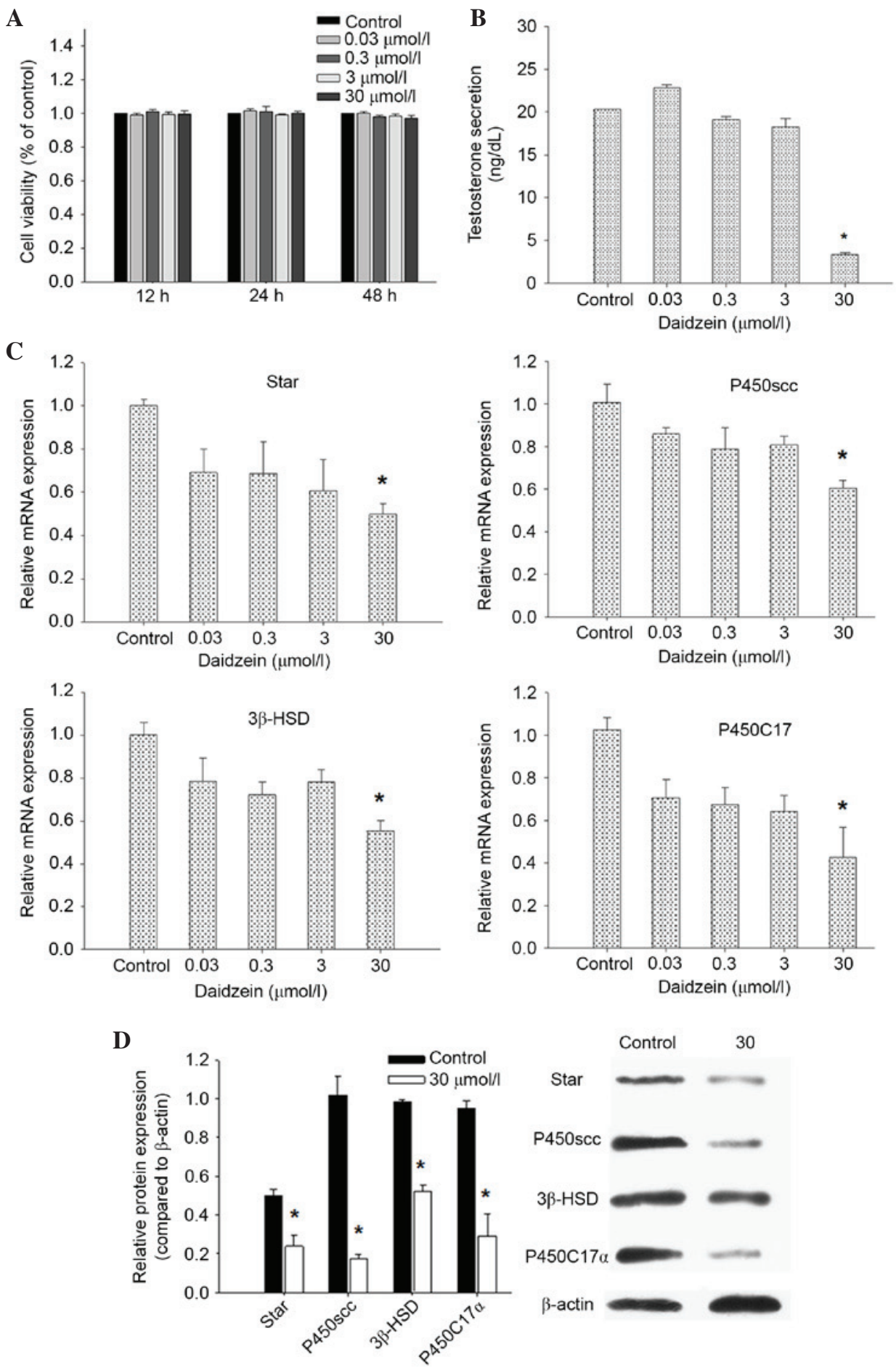

Figure 3. Effects of daidzein on testosterone production, and the expression of StAR and steroidogenic enzymes in Leydig cells. (A) Cell viability assessment in Leydig cells. (B) Testosterone secretion in Leydig cells, in the absence or presence of daidzein. (C) Quantitative polymerase chain reaction analyses of mRNA expression in primary cultured Leydig cells. (D) Western blot analysis of StAR, P450scc, 33-HSD, P450C17 $\alpha$ and $\beta$-actin expression in Leydig cells. A representative gel is shown. Densitometric analysis of StAR, P450scc, 3 $\beta$-HSD and P450C17 $\alpha$ expression to $\beta$-actin expression was conducted. Data are presented as the mean \pm standard error. ${ }^{*} \mathrm{P}<0.05$ vs. control. StAR, steroidogenic acute regulatory protein; $\mathrm{P} 450$ scc, anti-cholesterol side chain cleavage enzyme; $3 \beta$-HSD, $3 \beta$-hydroxysteroid dehydrogenase; $\mathrm{P} 450 \mathrm{C} 17 \alpha, 17 \alpha$-hydroxylase/20-lyase.

Daidzein inhibits Sertoli cell proliferation in cultured neonatal mouse testes. To investigate the effects of daidzein exposure on Sertoli cells in mouse testes, cell proliferation was analyzed with BrdU staining. A total of 3 hours after BrdU was mixed into the culture system, some labeled cells were observed in the seminiferous tubules and in the interstitium of the testes. The number of labeled Sertoli cells was reduced in the testes following treatment with $30 \mu \mathrm{mol} / 1$ daidzein (Fig. 4A and B).

Daidzein inhibits vimentin expression in cultured neonatal mouse testes. To further determine the effects of daidzein on Sertoli cells in neonatal testes, the expression levels of vimentin were analyzed. Vimentin mRNA expression levels 

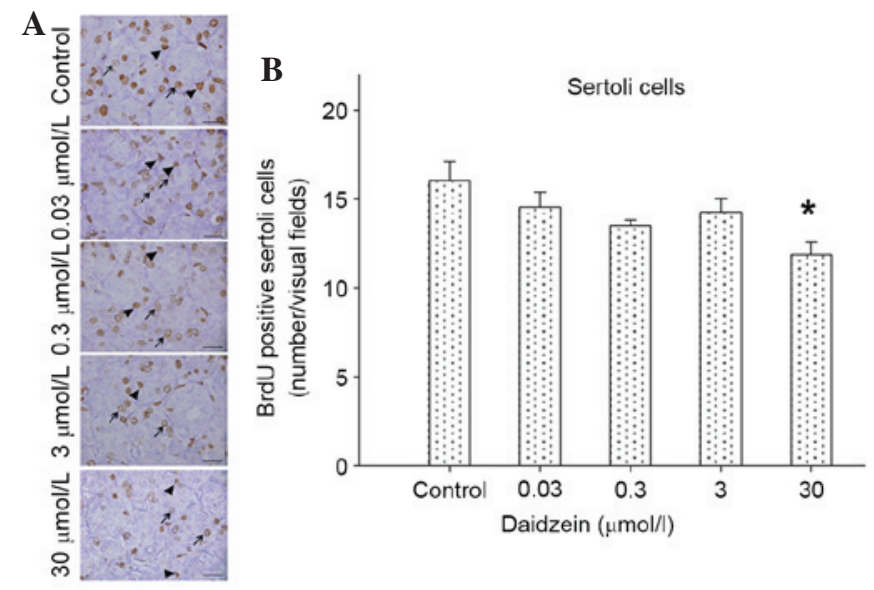

Figure 4. Proliferation of Sertoli cells in daidzein-treated testes. (A) At the end of the culture period, sections of seminiferous tubules were stained with hematoxylin and eosin, and antibodies against BrdU to detect proliferation. Sertoli cells were identified by morphology. Arrowheads indicate Sertoli cells; arrows indicate spermatogonia. Scale bars $=20 \mu \mathrm{m}$. (B) Number of BrdU-positive Sertoli cells in testes. Mean number of positive Sertoli cells was calculated from ten visual fields selected in each slide; six slides were analyzed per group. Data are presented as the mean \pm standard error of the mean $(\mathrm{n}=6)$. ${ }^{*} \mathrm{P}<0.05$ vs. control. BrdU, 5'-bromo-2'-deoxyridine.
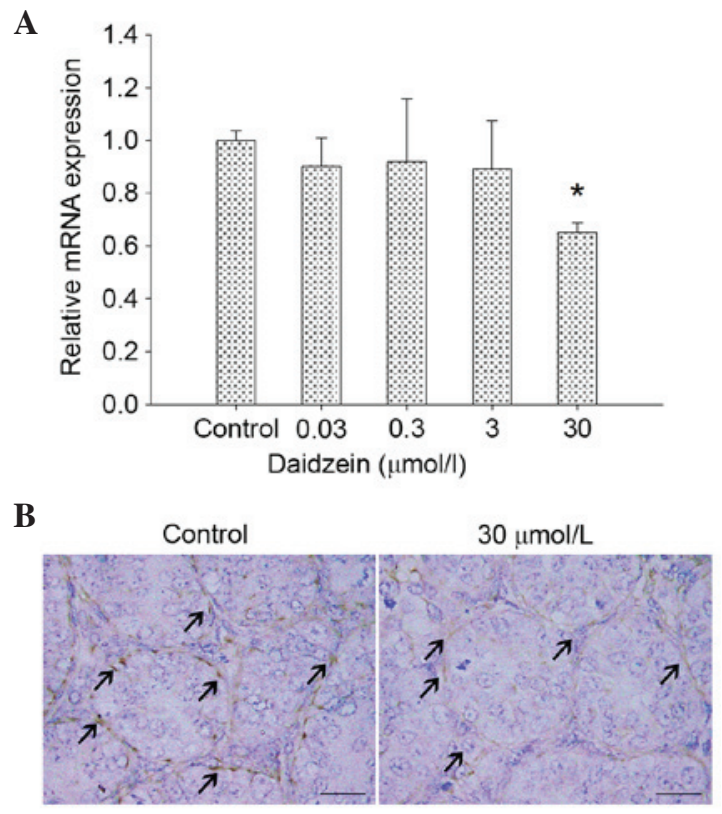

Figure 5. Expression of vimentin in testes. (A) Quantitative polymerase chain reaction analyses of vimentin mRNA expression in control and daidzein-exposed testes. Data are presented as the mean \pm standard error $(n=3)$. ${ }^{*} \mathrm{P}<0.05$ vs. control. (B) Immunohistochemical staining of vimentin in testes. Arrows indicate stained vimentin in Sertoli cells lining the seminiferous cords. Scale bars $=20 \mu \mathrm{m}$.

were markedly lower following treatment with $30 \mu \mathrm{mol} / 1$ daidzein compared with the control $(\mathrm{P}<0.05$; Fig. 5A). In addition, immunostaining of Sertoli cells in daidzein-treated $(30 \mu \mathrm{mol} / \mathrm{l})$ testes was weaker compared with the control (Fig. 5B).

Exposure to daidzein has no effect on inhibin B expression in neonatal mouse testes. The effects of daidzein on the expression levels of inhibin $\mathrm{B}$, which is a regulator involved in steroidogenesis, were also analyzed. As shown in Fig. 6A,
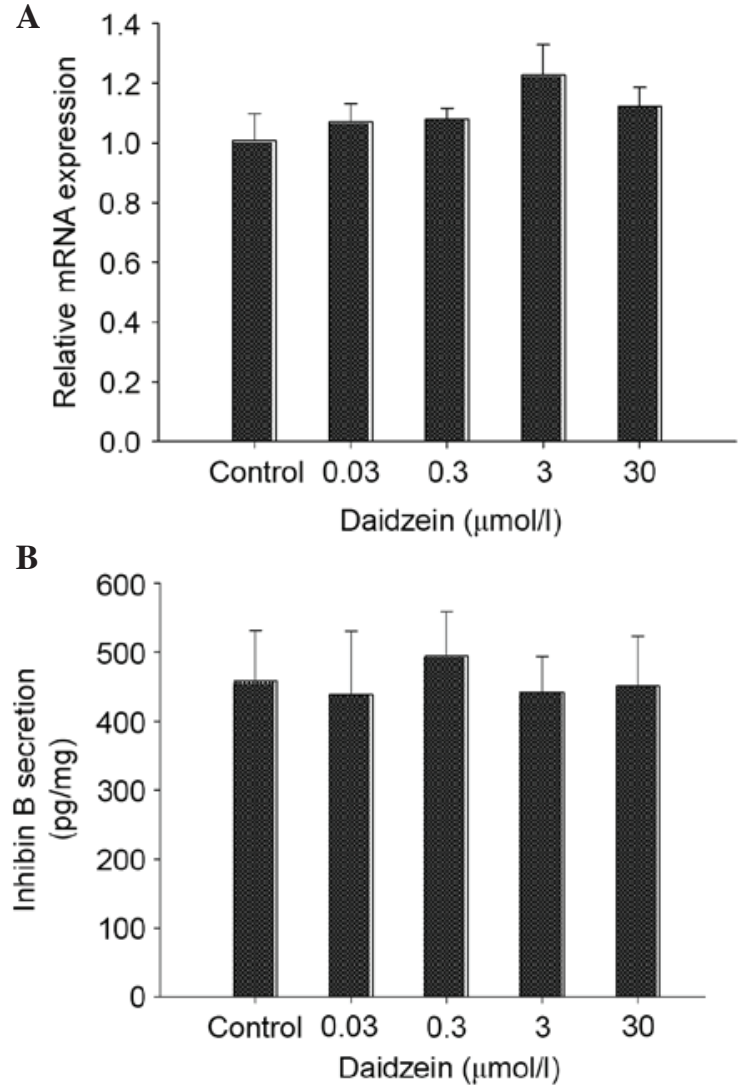

Figure 6. Expression of inhibin B in testes. (A) Quantitative polymerase chain reaction analyses of inhibin $B$ mRNA expression in control and daidzein-exposed testes. (B) Inhibin B secretion in testes cultured in the absence or presence of daidzein. Data are presented as the mean \pm standard error $(n=3)$.

the mRNA expression levels of inhibin B exhibited no alteration following treatment with daidzein. Consistent with this result, the levels of inhibin $B$ secreted by testes exhibited no difference between daidzein-treated testes and controls (Fig. 6B).

\section{Discussion}

Daidzein is an active isoflavone, which is widely consumed in the East. The present study focused on the effects of daidzein on testosterone biosynthesis and Sertoli cell function in neonatal mouse testes. The results demonstrated that daidzein was able to decrease testosterone synthesis in vitro, and the decrease was preceded by alterations in related protein expression, e.g. StAR, P450scc and 3 $\beta$-HSD. In addition, the present data illustrated that high doses of daidzein may exert adverse effects on Sertoli cells in neonatal mouse testes.

The present study investigated the effects of daidzein on testes during the early neonatal period in vitro using a testis culture system, since the dose of delivered isoflavone to pups via milk is difficult to control. The dose has been shown to be thousands of times lower compared with the dose delivered by maternal diet (28). Furthermore, the period of infancy is much longer in humans than it is in mice. Therefore, the testis culture method was chosen to determine the direct effects of daidzein on early neonatal mouse testes (PDN4). 
Testis culture was initially used in reproductive physiology studies, including those focused on spermatogenesis, meiosis and development (29-32). In addition, the organ culture method has been used to develop novel applications in toxicological studies, allowing in vitro functional screening tools to select exogenous compounds for further in vivo evaluation $(33,34)$. Cell lines or primary cultures are limited, since most only poorly mimic the physiological situation; however, organ culture can preserve intercellular relationships in tissue (35).

The present study demonstrated that short exposure to high concentrations of daidzein may lead to reduced testosterone levels, without histopathological changes, in neonatal mouse testes, which consisted with the results of a previous study (10). Pan et al reported that genistein exposure at 20 and $100 \mathrm{mg} / \mathrm{kg} /$ day was able to adversely affect testosterone production (15). Furthermore, Lehraiki et al reported that genistein impairs early testosterone production in fetal mouse testes in vitro (22). Genistein at a dose of $213 \mathrm{mg} / \mathrm{kg} . \mathrm{bw} / \mathrm{day}$ from gestational day 7 to PND13 also reduced plasma testosterone levels in rat offspring (36). Similarly, a clear downtrend tendency in plasma testosterone levels was detected in primary Leydig cells treated with $30 \mu \mathrm{mol} / 1$ daidzein, which is similar to the results of Opalka et al $(37,38)$. Nevertheless, no adverse effect on proliferation was detected in Leydig cells treated with $30 \mu \mathrm{mol} / 1$ daidzein. The present findings identified a potential harmful effect of daidzein exposure on testis steroidogenesis function during the early neonatal period.

Although the association between isoflavone exposure and reduced testosterone production has been defined, the toxicant mechanism remains unclear. Suppression of StAR and steroidogenic enzymes (P450scc, 3 $\beta$-HSD and $\mathrm{P} 450 \mathrm{C} 17 \alpha$ ) has been suggested as toxicant mechanisms underlying reduced testosterone levels $(39,40)$. Testosterone production can be inhibited by exogenous compounds via the suppression of StAR, P450scc and $3 \beta-H S D(41,42)$. The present results detected reduced expression levels of StAR, P450scc and 3 $\beta$-HSD in the neonatal testes when treated with a high concentration of daidzein. Consistent with this result, it has previously been reported that genistein, another type of isoflavone, suppresses StAR, P450scc, 3 $\beta$-HSD and $\mathrm{P} 450 \mathrm{C} 17$ expression, and decreases testosterone production in fetal testes (22). These findings may explain why testosterone levels in the testis or plasma are decreased following treatment with isoflavones.

Concurrently, the expression levels of StAR and steroidogenic enzymes were assessed in daidzein-treated Leydig cells, in order to further verify the mechanistic activities of daidzein on factors associated with steroid synthesis. The results demonstrated an apparent decline in mRNA and protein expression levels of StAR, P450scc, 3ß-HSD and P450C17, which are consistent with the organ culture results. With regards to $\mathrm{P} 450 \mathrm{C} 17 \alpha$, the discrepancy in expression levels between the testes and Leydig cells may be due to different levels of sensitivity to isoflavones. Leydig cells are known to be more sensitive to exogenous agents compared with organ culture (43).

Prior to the onset of puberty, immature Sertolicells proliferate in parallel to spermatogonia until the seminiferous epithelium reaches its final size (44). Our previous study indicated that isoflavone exposure can downregulate follicle-stimulating hormone receptor, transferrin and vimentin mRNA expression in Sertoli cells in vitro (45). The present results demonstrated that $30 \mu \mathrm{mol} / 1$ daidzein was able to interfere with Sertoli cell proliferative activity in neonatal mouse testes in vitro, thus implying a potential adverse effect on spermatogenesis.

The present study also detected reduced expression levels of vimentin, which is an essential Sertoli cell cytoskeletal protein, following treatment with daidzein. Previous studies have demonstrated that endocrine disruptors can alter the expression of vimentin in vitro and in vivo $(46,47)$. In the present study, the mRNA and protein expression levels of vimentin were reduced in daidzein-exposed testes; these results are similar to our previous study (45). These findings demonstrated that vimentin may be sensitive to daidzein treatment. Reduced vimentin expression may help to explain the increased germ cell apoptosis, which was observed in China mini-pig boars following exposure to $250 \mathrm{ppm}$ soy isoflavone for 60 days (12). The association between altered vimentin expression and reproductive toxicity due to isoflavone exposure remains unclear. Therefore, further research is required to clarify these associations and the mechanisms by which isoflavone exerts effects on vimentin expression.

Inhibin B, which is secreted by Sertoli cells, reflects spermatogenesis function in the testes, and, is an essential biomarker of reproductive toxicity. Concentration of inhibin B is correlated with testicular histology structure (48), sperm concentration and sperm count (49). Decreased inhibin B levels may predict impaired secretory function of Sertoli cells and damaged testicular spermatogenesis (50). However, in the present study, no clear effects on inhibin B mRNA expression were detected in the neonatal testes. Similarly, concentrations of inhibin B in the supernatant were not altered in testes exposed to daidzein in vitro. Therefore, inhibin B may not be affected following daidzein exposure.

In conclusion, early neonatal exposure to daidzein elicits adverse effects on testosterone biosynthesis and Sertoli cell function. Daidzein exposure may inhibit the expression of StAR and steroidogenic enzymes (P450scc and 3 $\beta$-HSD). In addition, the results of the present study revealed that exposure to daidzein reduces the expression of vimentin in Sertoli cells, predicting a potential adverse effect on sperm development. Therefore, these results indicate that isoflavones exert potential harmful effects on immature testes; however, the detailed mechanism of action of this phytochemical remains to be elucidated. Further studies investigating the effects of isoflavones on Sertoli cells are required to adequately understand the role of isoflavones in sperm development.

\section{Acknowledgements}

Financial support for this study was provided by the National Natural Science Foundation of China (grant no. 81072309).

\section{References}

1. Kurzer MS and Xu X: Dietary phytoestrogens. Annu Rev Nutr 17: 353-381, 1997.

2. Coward L, Barnes NC, Setchell KDR and Barnes S: Genistein, daidzein, and their $\beta$-glycoside conjugates: Antitumor isoflavones in soybean food from American and Asian diets. J Agri Food Chem 41: 1961-1967, 1993.

3. Morton MS, Arisaka O, Miyake N, Morgan LD and Evans BA: Phytoestrogen concentrations in serum from Japanese men and women over forty years of age. J Nutr 132: 3168-3171, 2002. 
4. McCarver G, Bhatia J, Chambers C, Clarke R, Etzel R, Foster W, Hoyer P, Leeder JS, Peters JM, Rissman E, et al: NTP-CERHR expert panel report on the developmental toxicity of soy infant formula. Birth Defects Res B Dev Reprod Toxicol 92: 421-468, 2011.

5. Lagari VS and Levis S: Phytoestrogens for menopausal bone loss and climacteric symptoms. J Steroid Biochem Mol Biol 139: 294-301, 2014.

6. Magee PJ and Rowland I: Soy products in the management of breast cancer. Curr Opin Clin Nutr Metab Care 15: 586-591, 2012.

7. Adjakly M, Ngollo M, Boiteux JP, Bignon YJ, Guy L and Bernard-Gallon D: Genistein and daidzein: Different molecular effects on prostate cancer. Anticancer Res 33: 39-44, 2013.

8. Liu ZM, Ho SC, Chen YM and Ho YP: The effects of isoflavones combined with soy protein on lipid profiles, C-reactive protein and cardiovascular risk among postmenopausal Chinese women Nutr Metab Cardiovasc Dis 22: 712-719, 2012.

9. Jungbauer A and Medjakovic S: Phytoestrogens and the metabolic syndrome. J Steroid Biochem Mol Biol 139: 277-289, 2014.

10. Rozman KK, Bhatia J, Calafat AM, Chambers C, Culty M, Etzel RA, Flaws JA, Hansen DK, Hoyer PB, Jeffery EH, et al: NTP-CERHR expert panel report on the reproductive and developmental toxicity of genistein. Birth Defects Res B Dev Reprod Toxicol 77: 485-638, 2006.

11. Akingbemi BT, Braden TD, Kemppainen BW, Hancock KD, Sherrill JD, Cook SJ, He X and Supko JG: Exposure to phytoestrogens in the perinatal period affects androgen secretion by testicular Leydig cells in the adult rat. Endocrinology 148: 4475-4488, 2007.

12. Yuan XX, Zhang B, Li LL, Xiao CW, Fan JX, Geng MM and Yin YL: Effects of soybean isoflavones on reproductive parameters in Chinese mini-pig boars. J Anim Sci Biotechnol 3: 31, 2012.

13. Caceres S, Pena L, Moyano G, Martinez-Fernandez L, Monsalve B, Illera MJ, Millan P, Illera JC and Silvan G: Isoflavones and their effects on the onset of puberty in male Wistar rats. Andrologia 47: 1139-1146, 2015.

14. Huang Y, Pan L, Xia X, Feng Y, Jiang C and Cui Y: Long-term effects of phytoestrogen daidzein on penile cavernosal structures in adult rats. Urology 72: 220-224, 2008.

15. Pan L, Xia X, Feng Y, Jiang $C$ and Huang Y: Exposure to the phytoestrogen daidzein attenuates apomorphine-induced penile erection concomitant with plasma testosterone level reduction in dose- and time-related manner in adult rats. Urology 70: 613-617, 2007.

16. Hu GX, Zhao BH, Chu YH, Zhou HY, Akingbemi BT, Zheng ZQ and Ge RS: Effects of genistein and equol on human and rat testicular 3beta-hydroxysteroid dehydrogenase and 17beta-hydroxysteroid dehydrogenase 3 activities. Asian J Androl 12: 519-526, 2010

17. Chavarro JE, Toth TL, Sadio SM and Hauser R: Soy food and isoflavone intake in relation to semen quality parameters among men from an infertility clinic. Hum Reprod 23: 2584-2590, 2008

18. Cederroth CR, Zimmermann C, Beny JL, Schaad O, Combepine C, Descombes P, Doerge DR, Pralong FP, Vassalli JD and Nef S: Potential detrimental effects of a phytoestrogen-rich diet on male fertility in mice. Mol Cell Endocrinol 321: 152-160, 2010.

19. Adachi T, Okuno Y, Takenaka S, Matsuda K, Ohta N, Takashima K, Yamazaki K, Nishimura D, Miyatake K, Mori C and Tsujimoto G: Comprehensive analysis of the effect of phytoestrogen, daidzein, on a testicular cell line, using mRNA and protein expression profile. Food Chem Toxicol 43: 529-535, 2005.

20. Pfaehler A, Nanjappa MK, Coleman ES, Mansour M, Wanders D, Plaisance EP, Judd RL and Akingbemi BT: Regulation of adiponectin secretion by soy isoflavones has implication for endocrine function of the testis. Toxicol Lett 209: 78-85, 2012.

21. Livera G, Delbes G, Pairault C, Rouiller-Fabre V and Habert R: Organotypic culture, a powerful model for studying rat and mouse fetal testis development. Cell Tissue Res 324: 507-521, 2006.

22. Lehraiki A, Chamaillard C, Krust A, Habert R and Levacher C: Genistein impairs early testosterone production in fetal mouse testis via estrogen receptor alpha. Toxicol In Vitro 25: 1542-1547, 2011.

23. Xu H, Huang J, Li M, Gao ZB, Zhu YF and Li Y: The effects of di- (2-ethylhexyl) phthalate (DEHP) in testosterone synthesis and its molecular mechanisms in the fetal testis of male mouse by organ culture in vitro. Sichuan Da Xue Xue Bao Yi Xue Ban 44: 511-516, 2013 (In Chinese)
24. Liu Y, Zhu YF, Gao ZB, Li M, Zhong LY, Yin DJ and Li Y: Establishment of a rotary aerobic culture system for in vitro culture of mouse testis. Nan Fang Yi Ke Da Xue Xue Bao 35: 66-71, 2015 (In Chinese).

25. Li Y and Yu ZL: Effect of zinc on bone metabolism in fetal mouse limb culture. Biomed Environ Sci 15: 323-329, 2002.

26. Liu JZ, Guo HB, Deng CH, Ou YH and Peng AP: The culture and identification of rat testis Leydig cell. Zhonghua $\mathrm{Nan} \mathrm{Ke}$ Xue 12: 14-17, 2006 (In Chinese).

27. Livak KJ and Schmittgen TD: Analysis of relative gene expression data using real-time quantitative PCR and the 2(-Delta Delta C(T)) Method. Methods 25: 402-408, 2001.

28. Doerge DR, Twaddle NC, Churchwell MI, Newbold RR and Delclos KB: Lactational transfer of the soy isoflavone, genistein, in Sprague-Dawley rats consuming dietary genistein. Reprod Toxicol 21: 307-312, 2006.

29. Steinberger A and Steinberger E: Differentiation of rat seminiferous epithelium in organ culture. J Reprod Fertil 9: 243-248, 1965.

30. Yokonishi T, Sato T, Katagiri K and Ogawa T: In vitro spermatogenesis using an organ culture technique. Methods Mol Biol 927: 479-488, 2013.

31. Sato T, Katagiri K, Gohbara A, Inoue K, Ogonuki N, Ogura A, Kubota Y and Ogawa T: In vitro production of functional sperm in cultured neonatal mouse testes. Nature 471: 504-507, 2011.

32. Sato T, Katagiri K, Kubota Y and Ogawa T: In vitro sperm production from mouse spermatogonial stem cell lines using an organ culture method. Nat Protoc 8: 2098-2104, 2013.

33. Lehraiki A, Racine C, Krust A, Habert R and Levacher C: Phthalates impair germ cell number in the mouse fetal testis by an androgen- and estrogen-independent mechanism. Toxicol Sci 111: 372-382, 2009.

34. Lambrot R, Livera G, Coffigny H, Pairault C, Frydman R, Habert R and Rouiller-Fabre V: A new method for toxicity assays on human and mouse fetal testis. Biochimie 88 : 1831-1835, 2006.

35. Auger J, Eustache F, Rouiller-Fabre V, Canivenc-Lavier MC and Livera G: Integrative rodent models for assessing male reproductive toxicity of environmental endocrine active substances. Asian J Androl 16: 60-70, 2014

36. Boberg J, Mandrup KR, Jacobsen PR, Isling LK, Hadrup N, Berthelsen L, Elleby A, Kiersgaard M, Vinggaard AM, Hass U and Nellemann C: Endocrine disrupting effects in rats perinatally exposed to a dietary relevant mixture of phytoestrogens. Reprod Toxicol 40: 41-51, 2013

37. Opalka DM, Kaminska B, Piskula MK, Puchajda-Skowronska H and Dusza L: Effects of phytoestrogens on testosterone secretion by Leydig cells from Bilgoraj ganders (Anser anser). Br Poult Sci 47: 237-245, 2006

38. Opalka M, Kaminska B, Leska A and Dusza L: Mechanism of phytoestrogen action in Leydig cells of ganders (Anser anser domesticus): Interaction with estrogen receptors and steroidogenic enzymes. J Environ Sci Health A Tox Hazard Subst Environ Eng 47: 1335-1339, 2012.

39. Hannas BR, Lambright CS, Furr J, Evans N, Foster PM, Gray EL and Wilson VS: Genomic biomarkers of phthalate-induced male reproductive developmental toxicity: A targeted RT-PCR array approach for defining relative potency. Toxicol Sci 125: 544-557, 2012.

40. Ye L, Su ZJ and Ge RS: Inhibitors of testosterone biosynthetic and metabolic activation enzymes. Molecules 16: 9983-10001, 2011.

41. Liu S, Wang D, Zhang J, Zhang D, Gong M, Wang C, Wei N, Liu W, Wang Y, Zhao C, et al: Citrinin reduces testosterone secretion by inducing apoptosis in rat Leydig cells. Toxicol In Vitro 26: 856-861, 2012.

42. N'Tumba-Byn T, Moison D, Lacroix M, Lecureuil C, Lesage L, Prud'homme SM, Pozzi-Gaudin S, Frydman R, Benachi A, Livera G, et al: Differential effects of bisphenol A and diethylstilbestrol on human, rat and mouse fetal Leydig cell function. PLoS One 7: e51579, 2012.

43. Delbès G, Duquenne C, Szenker J, Taccoen J, Habert R and Levacher C: Developmental changes in testicular sensitivity to estrogens throughout fetal and neonatal life. Toxicol Sci 99: 234-243, 2007

44. Ryser S, Glauser D, Vigier M, Zhang YQ, Tachini P, Schlegel W, Durand $P$ and Irminger-Finger I: Gene expression profiling of rat spermatogonia and Sertoli cells reveals signaling pathways from stem cells to niche and testicular cancer cells to surrounding stroma. BMC Genomics 12: 29, 2011. 
45. Yin D, Zhu Y, Liu L, Xu H, Huang J and Li Y: Potential detrimental effect of soy isoflavones on testis sertoli cells. Zhong Nan Da Xue Xue Bao Yi Xue Ban 39: 598-604, 2014 (In Chinese)

46. Feng Y,Fang X, Shi Z, Xu M and Dai J: Effects of PFNA exposure on expression of junction-associated molecules and secretory function in rat Sertoli cells. Reprod Toxicol 30: 429-437, 2010.

47. Tay TW, Andriana BB, Ishii M, Tsunekawa N, Kanai Y and Kurohmaru M: Disappearance of vimentin in Sertoli cells: A mono(2-ethylhexyl) phthalate effect. Int J Toxicol 26: 289-295, 2007.
48. Pierik FH, Vreeburg JT, Stijnen T, De Jong FH and Weber RF: Serum inhibin B as a marker of spermatogenesis. J Clin Endocrinol Metab 83: 3110-3114, 1998.

49. Andersson AM, Petersen JH, Jørgensen N, Jensen TK and Skakkebaek NE: Serum inhibin B and follicle-stimulating hormone levels as tools in the evaluation of infertile men: Significance of adequate reference values from proven fertile men. J Clin Endocrinol Metab 89: 2873-2879, 2004

50. Monsees TK, Franz M, Gebhardt S, Winterstein U, Schill WB and Hayatpour J: Sertoli cells as a target for reproductive hazards. Andrologia 32: 239-246, 2000. 